\title{
The Influence of Topical Application of Acetone Solution of Cucurbitacin-A at 48 Hours After the Fourth Moult on the Parameters of Cocoon Spinned by Mature Fifth Instar Larvae of Silkworm, Bombyx mori (L) [Race: Double Hybrid - (CSR6 x CSR26) x CSR2 x CSR27)]
}

\author{
Dipali Dattatraya Ghanvat ${ }^{1}$ and Vitthalrao Bhimasha Khyade ,2, $^{\text {* }}$
}

${ }^{1}$ Department of Microbiology, Shardabai Pawar Mahila Mahavidyalaya, Shardanagar Tal. Baramati Dist. Pune - 413115 (India)

${ }^{2}$ Sericulture Unit, Malegaon Sheti Farm, Agricultural Development Trust Baramati, Shardanagar, (Malegaon Khurd) Post Box No - 35, Baramati, Pune 413 115, Maharashtra,

${ }^{3}$ Department of Zoology, Shardabai Pawar Mahila Mahavidyalaya, Shardanagar Tal. Baramati Dist. Pune -413115, India

*Corresponding author

\section{A B S T R A C T}

The topical application of acetone solution of Cucurbitacin-A at 48 hours after the

\section{Keywords}

Topical application, Acetone Solution, Cocoon, Bombyx mori

Article Info

Accepted:

08 January 2020

Available Online:

10 February 2020 fourth moult to the fifth instared larvae of silkworm, Bombyx mori (L) [Race: Double Hybrid - (CSR6 x CSR26) x CSR2 x CSR27)] was found significant influence on the parameteres of the silk cocoon and silk fibre. The weight of whole cocoon (deflossed), silk shell weight, weight of pupa and silk shell percentage or ratio in the group receipient of topical application of acetone solution of Cucurbitacin-A at 48 hours after the fourth moult was recorded $2.786^{* *}( \pm 0.558) ; 0.917 * *( \pm 0.057) ; 1.869$ and $32.914^{* * *}$ respectively. The length of silk fibre (in meter); weight of silk fibre (in gram) and denier scale silk fibre obtained through reeling the cocoons harvested from the group of larvae receipient of topical application of acetone solution of Cucurbitacin-A at 48 hours after the fourth moult were recorded $1476.36^{*}( \pm 128.51) ; 0.793 * *( \pm 0.114)$ and $4.834 * * *$ respectively.

\section{Introduction}

The plants are the richest source of nutrients for the life on earth. Most of the plant derived chemical nutrient compounds are used by animals as their food material. In practical sense, plants are synthesizing the chemical nutrients and other chemical compounds for their own lives. The chemical nutrient entitled, "Cucurbitacin" is serving a lot in the plants of family: Cucurbitaceae for defense against the herbivores. The common pumpkins and gourds are the members of this laureal family: Cucurbitaceae. With reference 
to chemical aspects, the cucurbitacin is a member of class: terpene and subclass: triterpene. According to Chen, et al., (2005, 2008), the nutrient chemical cucurbitacin is formally derived from cucurbitane. This cucurbitane is a triterpene hydrocarbonspecifically, from the unsaturated variant cucurbita-5-ene, or $19-(10 \rightarrow 9 \beta)$-abeo-10 $\alpha$ lanost-5-ene. Naturally, biochemicals of class: cucurbitane compounds found in glycoside form.

Alghasham (2013), reported the cucurbitacins and the derivatives of cucurbitacins in the plants of many families. The plant families with cucubitacins include family: Brassicaceae; family: Cucurbitaceae; family: Scrophulariaceae; family: Begoniaceae; family: Elaeocarpaceae; family: Datiscaceae; family: Desfontainiaceae; family: Polemoniaceae; family: Primulaceae; family: Rubiaceae; family: Sterculiaceae; family: Rosaceae, and family: Thymelaeaceae. According to Alghasham (2013), the cucurbitacins are also found in some mushrooms (examples: Russula and Hebeloma) in some marine species of animals of phylum: mollusca.

Kapoor (2013) reported taste deterrent nature of cucurbitacins in plants foraged by some animals. and in some edible plants preferred by humans, like cucumbers. In laboratory research, cucurbitacins have cytotoxic properties and are under study for their potential biological activities. The significant biological characters, such as toxicity and potent pharmacological utilization for development of medicines for treating inflammation, tumor, heart diseases, and diabetic complications made cucurbitacins to occupy the key position in pure and applies sciences (Kaushik, et al., 2015). The "toxic squash syndrome" is the term used for the toxicity concerned with consumption of natural or functional food material with higher content of in cucurbatins (Kusin, et al., 2012). Assouly P (May 2018) reported sickness involving nausea, vomiting, diarrhea and hair loss weeks later through the consumption of soup prepared through the use of bitter pumpkins. Le Roux, et al., (2018) reported similar acute illness through the consumption of squash from bitter gourds. Rymal, et al., (1984) mentioned that, cross pollination with wild species could results the higher concentration of toxin in the plants. According to Mashilo, et al., (2018), stress due to higher temperature in the tenure of growth may also results the higher concentration of toxin in the plants. With reference to anticancer activity, cucurbitacin deserve four common and most significant variants. These four common and most significant variants of cucurbitacin include: Cucurbitacin-B; Cucurbitacin-D, Cucurbitacin-E and Cucurbitacin-I. According to Chen X, et al., (2012), the Cucurbitacin-B and the Cucurbitacin-D are the most common in plants. The inhibition of "Signal Trancducer and Activator of Transcription - 3" (or STAT - 3); induction of apoptosis and cell cycle arrest are the mechanisms through which cucurbitacin affects cancer cells. Wagner (2015) reported death of 79-year-old man who died in BadenWürttemberg, Germany, shortly after eating a casserole (a dish made by cooking meat, vegetables, or other foods) containing zucchini (summer squash) he had received from a neighbor.

Specific titer of the insect "Juvenile Hormone" (JH) \& the specific titer of insect "Moulting Hormone" (MH) perform the role to orchestrate the progression of the insect metamorphosis. In the insects, like silkworm, Bombyx mori (L), the corpora allata of cephalic region secrete insect "Juvenile Hormone" (JH). The prothorasic glands secrete insect "Moulting Hormone" (MH). The working of the insect "Juvenile 
Hormone" (JH) \& the insect "Moulting Hormone" (MH) is exactly opposite to each other. The titer of the insect "Juvenile Hormone" (JH) maintains the larval or juvenile stage through many physiological mechanisms including inhibition of chitin deposition. The insect "Juvenile Hormone" (JH) recommends juvenile stage of insect life. The insect "Moulting Hormone" (MH) allows the chitin deposition and proceeds the age of insect life. Inhibition of morphogenetic programme at predetermined and group specific ontogenetic positions is the distinguishing feature of JH (Zaoral Slama, 1970). Insect metamorphosis is the intigrative product of fruitful interplay of specific titer of the insect "Juvenile Hormone" $(\mathrm{JH}) \&$ the specific titer of insect "Moulting Hormone" (MH).

There are many chemical compounds of plant origin, animal origin (and synthetic too) that exhibit the biochemical properties of natural the insect "Juvenile Hormone" ( $\mathrm{JH})$ (\& the insect "Moulting Hormone" MH too). Williams (1956) designated the compounds of plant origin, animal origin (and synthetic too) that exhibit the biochemical properties of natural the insect "Juvenile Hormone" ( $\mathrm{JH})$ "Juvenoids". Increase in the larval age seems to be the significant influence exerted through the exogenous topical application of acetone solutions of the juvenoids. Further, the juvenoids obtained from plant material through suitable solvent are reported potent activity through massive turnover, alteration of constituency of metabolites like proteins, lipids, carbohydrates, aminoacids, fatty acids \& chitin too Gopakumar et al., (1977); Slama (1979); Khyade et al., (2002); Khyade et al., (2003)\& Khyade (2004). The juvenile hormone $(\mathrm{JH})$ and juvenile hormone analogues (JHA or juvenoids) are well known to improve the physiological status of larval body of insects. Therefore, juvenile hormone analogues (JHA or juvenoids) have been tried for qualitative improvement of silk Grenier \& Grenier (1983); Kamimura \& Kikichi (1998); Ratnasen (1988); Mamatha et al., (1999) \& Khyade (2002, 2003 \& 2004).

The class: terpene is a large and diverse group of organic compounds. The terpenes are produced by a diverse group of plants. The plants of "Conifers" are recognized for the production of the terpenes (Eberhard Breitmaier, 2006 and Davis, et al., 2000). The terpenes often have a strong odor. The terpenes protect the plants that produce them by deterring herbivores and by attracting predators and parasites of herbivores (Martin, et al., 2003; Pichersky, 2996). The juvenoid action of terpenes (Vitthalrao B. Khyade and Karel Slama, 2015) and terpene chemical nature of Cucurbitacin-A made to plan the attempt on utilization of acetone solution for topical application to the larval instars of silkworm, Bombyx mori (L).

\section{Materials and Methods}

The studies were carried out through: Preparation of Acetone Solution of cucurbitacin; Silkworm larval stages [Race: (CSR6 x CSR26) x CSR2 x CSR27)] rearing; Topical application of Acetone Solution of cucurbitacin to the larval instars of silkworm; Provision of Mountages for spinning the cocoon; Analysis of characters of cocoons; silk filament and Analysis of the data through method of statistics.

\section{Preparation of Acetone Solution of cucurbitacin}

The powder of Cucurbitacin-A was procured from Cayman Chemical 1180 East Ellsworth Road Ann Arbor, Michigan 48108 USA through local dealer. $0.5 \mathrm{mg}$ powder of Cucurbitacin-A was dissolved in $10 \mathrm{ml}$ acetone as a solvent. The strength of acetone solution of powder of Cucurbitacin-A was 50 
ppm (50 mg per litre). The solution was prepared freshly, ten minutes before its use for topical application to the fifth instar larvae of silkworm, Bombyx mori (L).

Rearing of silkworm larval stages [Race: Bivoltine Double Hybrid - (CSR6 x CSR26) x CSR2 x CSR27)]

Through the standard method prescribed by Krishnaswami, et al., (1978) for rearing of silkworm larvae appearing in the document authorized by Khyade (2004) and Vitthalrao B. Khyade, et al., (2005, 2006, 2007, 2008, 2009, 2010, 2011, 2012, 2013, 2014, 2015, 2016, and 2017) and through the use of leaves of mulberry, Morus alba (L), the rearing of silkworm instars was carried out. The DFLs (disease free layings) of double hybrid bivoltine race (CSR6 x CSR26) x CSR2 x CSR27) of silkworm, Bombyx mori (L) were procured through the "Dr. APIS" Laboratory and processed for black boxing, rearing of early instars, rearing of late age instars, regular feeding with leaves of mulberry, provision of mountage for spinning the cocoon and cocoon harvesting through the standard methods.

\section{Topical application of Acetone Solution of Cucurbitacin-A to the larval instars of silkworm}

The larval stage of silkworm, Bombyx mori (L) used in the attempt of topical application of acetone solution of powder of Cucurbitacin-A was the fifth instar. The larvae from the fourth bed were allowed for passing the fourth moult. Then, the larvae were transferred in the disinfected tray. The fifth instared larvae were grouped into three groups. Each group of larvae was in triplicate set. Each group of larvae in the attempt consisted of five hundred individuals. The three groups in the attempt include:
1. The "Untreated Control Group" of the fifth instar larvae;

2. The "Solvent / Acetone Treated Group" of the fifth instar larvae and

3. The "Cucurbitacin-A Treated Group" of the fifth instar larvae.

For the purpose of topical application, for the group of five hundred larvae of silkworm, Bombyx mori (L) [bivoltine double hybrid race: (CSR6 x CSR26) x CSR2 x CSR27)], 10 $\mathrm{ml}$ solution of powder of Cucurbitacin-A in acetone with strength of $50 \mathrm{ppm}$ (50 mg per litre) was utilized. Topical application of acetone solution of Cucurbitacin-A powder to the fifth instar larvae of silkworm, Bombyx mori (L) [bivoltine double hybrid race: (CSR6 x CSR26) x CSR2 x CSR27)] was carrird at forty eight hours after the fourth moult. Topical application of acetone solution of Cucurbitacin-A powder to the fifth instar larvae of silkworm, Bombyx mori (L) [bivoltine double hybrid race: (CSR6 x CSR26) x CSR2 x CSR27)] was in the form of spray. Household plastic hand sprayer was used. Thus, ten milliliter acetone solution of powder of cucurbitacin was topically applied (sprayed) to the group of five hundred fifth instared larvae of silkworm, Bombyx mori (L) [bivoltine double hybrid race: (CSR6 x CSR26) $x$ CSR2 x CSR27)] at forty eight hours after the fourth moult. The acetone treated group of five hundred fifth instared larvae of silkworm, Bombyx mori (L) [bivoltine double hybrid race: (CSR6 x CSR26) $x$ CSR2 x CSR27)] received ten milliter solvent acetone at forty eight hours after the fourth moult. Untreated group five hundred fifth instared larvae of silkworm, Bombyx mori (L) [bivoltine double hybrid race: (CSR6 x CSR26) x CSR2 x CSR27)] received no topical application.

For each day, four feedings were supplied at the rate 500 grams of mulberry leaves for the group of five hundred larvae. Rearing was 
carried out in the wooden trays. For each day, larvae received four feedings (at the rate of five hundred grams of mulberry leaves for the group of five hundred larvae for each feeding).

\section{Provision of Mountages for spinning the cocoon}

Mounting the mature fifth instared silkworm larvae is the last but one attempt in which the efforts put in for rearing larvae are realised in the form of a saleable product, the silky cocoon. In this attempt, either the mature silkworm larvae transferred to a suitable liame with proper anchor for spinning cocoons, called as mountages or suitable mountage is kept on the larvae in the rearing bed directly. Aim of both the processes is one and same. This process is called mounting. The mountage was made available for spinning the silky cocoon by the mature last larval stages (Khyade, 2004 and Vitthalrao B. Khyade, et al (2005, 2006, 2007, 2008, 2009, 2010, 2011, 2012, 2013, 2014, 2015, 2016, 2017 and 2018).

\section{Analysis of economic parameters}

The cocoons were harvested (separated from the mountage) on sixth day after the provision of mountage for spinning. Fifty cocoons from each group were selected randomly. Weight of each individual cocoon was recorded. Each individual cocoon was deflossed. The weight of individual deflossed cocoon was recorded. Each cocoon in particular group was cut vertically using the blade. The weight of individual pupa was recorded. For knowing the weght of silk shell of individual cocoon, the reading of the weight of pupa of respective group was subtracted from weight of respective individual deflossed cocoon. Weight of entire deflossed cocoon; weight of silk shell of individual cocoon and weight of pupa from individual cocoon were noted. The shell ratio of the cocoon is commercial or econic parameter. The shell ratio is the percentage of content of silk within the individual entire cocoon. The silk shell percentage (correctly called as shell ratio) was calculated through the use of readings of weight of whole deflossed cocoon and weight of silk shell in cocoon. The reading of silk shell weight was divided by reading of weight of whole cocoon without floss. The quotient thus obtained was processed for multiplication with hundred. Shell ratio or shell percentage is the outcome of this attempt. In sericulture, this silk shell percentage is called as shell ratio. Sericulture farmers get the price for the cocoon yield on the basis of "Shell Ratio".

The process of separation of silk fibre from the cocoon is recopgnized as reeling. The cocoons are cooked in hot water and the silk fibre is unwound from the cocoons. During reeling, the cocoons are processed in boiled water (at $95-97^{\circ} \mathrm{C}$ ) for $10-15$ minutes. This process of boilimg the cocoons in water is called as cooking. The process of boiling the cocoons or cooking the cocoons allows the gum like sericin around the fibroin content in silk filament. The process of boiling the cocoons or cooking the cocoons make reeling easy without breaks. Fifty cocoons from each group in the attempt were used for the purpose to reel the silk filament from individual cocoon. The charakha or Epprovate Machine was used for reeeling. The silk fibre length in meter (A) was obtained by using Eprovate. The silk fibre obtained from individual cocoon from individual group in the attempt was processed for recording the weight (in gram) (B). Length (in meter) (A) and weight (in gram) (B) of silk fibre were accounted for the calculation of Denier scale. The reading of weight of silk fibre (B) was divided by the reading of length of silk fibre (A). Quotient thus obtained was multiplied by 9000 for the purpose to get the denier scale of 
silk fibre (Vitthalrao B. Khyade and Abhilasha C. Bhunje, 20015 and 2016).

\section{Statistical Analysis of the data}

The statistical analysis involves collection and scrutinization of data sample. Statistical analysis can be divided into five different discrete steps. These steps include: description of the nature of the data to be used for analysis; exploration the relation of the data to the underlying group; establishment of the model to summarize understanding of how the data relates to the underlying group; establishment of proof for the validity of the model and to employ the "Predictive Analytics" to proceed the scenarios that will help to guide future actions. The final goal of analysis through statistical methods is to identify trends (Norman and Baily, 1955). The present attempts in experimentation were repeted for three times. The purpose of repetition of attempts in experimentation is to get the consistent results. The data, in the form of mean, standard deviation and percent change was collected. This data was subjected for statistical analysis. The statistical parameters considered in the attempt include: mean, standard deviation, percent variation and student " $\mathrm{t}$ " - test (Norman and Bailey, 1955; Vitthalrao B. Khyade and Manfred Eigen, 2018 www.iaiest.com).

\section{Results and Discussion}

The results on the attempt on the study on the influence of topical application of acetone solution of Cucurbitacin-A at 48 hours after the fourth moult on the parameters of Cocoon Spinned by Mature fifth instar larvae of silkworm, Bombyx mori (L) [Race: Double Hybrid - (CSR6 x CSR26) x CSR2 x CSR27)] are summarized in table- 1 and presented in Fig. 1,2,3 and 4.The weight (gm) of entire deflossed cocoon; weight of silk shell (gm) and the weight of Pupa (gm) of the Untreated
Control group were measured $1.947( \pm 0.389)$; $0.408( \pm 0.062)$ and 1.539 respectively. The ratio of silk shell to the entire cocoon in the group of "untreated control" was recorded 20.955. The weight (gm) of entire deflossed cocoon; weight of silk shell (gm) and the weight of Pupa (gm) of the acetone treated control group were measured $1.947( \pm 0.384)$; $0.408( \pm 0.109)$ and 1.539 respectively. The ratio of silk shell to the entire cocoon in the group of "acetone treated control group" was recorded 20.955 .

The readings $1163.28( \pm 99.284) ; 0.417$ $( \pm 0.088)$ and 3.226 belong respectively to the Silk Filament Length (SFL) (in meters); Silk Filament Weight (SFW) (in grams) and the denier scale of silk filament obtained from the untreated control group cocoons in the attempt (Table -1 and Fig. 1 and 2). The readings $1163.28( \pm 99.223) ; 0.417( \pm 0.091)$ and 3.226 belong respectively to the Silk Filament Length (SFL) (in meters); Silk Filament Weight (SFW) (in grams) and the denier scale of silk filament obtained from the acetone treated control group cocoons in the attempt (Table - 1 and Fig. 1 and 2).

The topical application of acetone solution of Cucurbitacin-A at 48 hours after the fourth moult to the fifth instared larvae of silkworm, Bombyx mori (L) [Race: Double Hybrid (CSR6 x CSR26) x CSR2 x CSR27)] was found significant influence on the parameteres of the silk cocoon and silk fibre. The weight of whole cocoon (deflossed), silk shell weight, weight of pupa and silk shell percentage or ratio in the group receipient of topical application of acetone solution of Cucurbitacin-A at 48 hours after the fourth moult was recorded 2.786** $( \pm 0.558)$; $0.917 * * \quad( \pm 0.057) ; \quad 1.869$ and $32.914 * * *$ respectively. The length of silk fibre (in meter); weight of silk fibre (in gram) and denier scale silk fibre obtained through reeling the cocoons harvested from the group 
of larvae receipient of topical application of acetone solution of Cucurbitacin-A at 48 hours after the fourth moult were recorded $1476.36 *( \pm 128.51) ; 0.793 * *( \pm 0.114)$ and $4.834 * * *$ respectively. The topical application of acetone solution of Cucurbitacin-A at 48 hours after the fourth moult to the fifth instared larvae of of silkworm, Bombyx mori (L) [Race: Double Hybrid - (CSR6 x CSR26) $x$ CSR2 $x$ CSR27)] was found resulted into significant improvement in the quantitative yield in the form of whole cocoon weight of 43.091 percentage and silk shell weight of 124.75 percentage. The shell ratio of the cocoons harvested from larval group receipient of topical application of acetone solution of Cucurbitacin-A at 48 hours after the fourth moult was found increased from 20.955 to 32.914 .

The denier scale is the textile unit of silk fibre. The "unit: tex" is more likely to be used in the countries like Canada and Continental Europe. The "unit: denier scale" remains more common in the United States and United Kingdom. The International System of Units uses kilogram per meter for linear density. The "unit: denier scale" is density per meter length of silk fibre. The "unit: denier scale" of silk fibre for untreated control group; acetone treated control group and Cucurbitacin-A treated group was found measured 3.226; 3.226 and 4.834 respectively.

Table.1 The Parameters of silk fibre and Cocoon Spinned by Mature fifth instar larvae of silkworm, Bombyx mori (L) [Race: Double Hybrid - (CSR6 x CSR26) x CSR2 x CSR27)] received topical application of acetone solution of Cucurbitacin-b at 48 hours after the fourth moult

\begin{tabular}{|c|c|c|c|}
\hline $\begin{array}{l}\text { Group } \\
\text { Parameters }\end{array}$ & $\begin{array}{c}\text { Untreated Control } \\
\text { Group }\end{array}$ & $\begin{array}{l}\text { Acetone Treated } \\
\text { Control Group }\end{array}$ & $\begin{array}{l}\text { Cucurbitacin-b } \\
\text { Treated Group }\end{array}$ \\
\hline $\begin{array}{l}\text { Whole Cocoon } \\
\text { Weight }(\mathrm{gm})(\mathrm{A})\end{array}$ & $\begin{array}{c}1.947 \\
( \pm 0.389) \\
00.000\end{array}$ & $\begin{array}{c}1.947 \\
( \pm 0.394) \\
00.000\end{array}$ & $\begin{array}{c}2.786 * * \\
( \pm 0.558) \\
43.091\end{array}$ \\
\hline Shell Weight $(\mathrm{gm})(\mathrm{B})$ & $\begin{array}{c}0.408 \\
( \pm 0.062) \\
00.000\end{array}$ & $\begin{array}{c}0.408 \\
( \pm 0.069) \\
00.000\end{array}$ & $\begin{array}{c}0.917 * * \\
( \pm 0.057) \\
124.75\end{array}$ \\
\hline $\begin{array}{l}\text { Shell Ratio }[(B \div A) \\
x 100]\end{array}$ & $\begin{array}{l}20.955 \\
00.000\end{array}$ & $\begin{array}{l}20.955 \\
00.000\end{array}$ & $\begin{array}{c}32.914 * * * \\
11.959\end{array}$ \\
\hline $\begin{array}{l}\text { Silk Filament Length } \\
\text { (meter) }(\mathrm{C})\end{array}$ & $\begin{array}{c}1163.28 \\
( \pm 99.284) \\
00.000\end{array}$ & $\begin{array}{c}1163.28 \\
( \pm 99.223) \\
00.000\end{array}$ & $\begin{array}{c}1476.36^{*} \\
( \pm 128.51) \\
26.913\end{array}$ \\
\hline $\begin{array}{l}\text { Silk Filament } \\
\text { Weight (gm) (D) }\end{array}$ & $\begin{array}{c}0.417 \\
( \pm 0.088) \quad 00.000\end{array}$ & $\begin{array}{c}0.417 \\
( \pm 0.091) \quad 00.000\end{array}$ & $\begin{array}{c}0.793 * * \\
( \pm 0.114) \quad 88.249\end{array}$ \\
\hline $\begin{array}{l}\text { Denier Scale of Silk } \\
\text { Filament } \\
{[(\mathrm{D} \div \mathrm{C}) \times 9000]}\end{array}$ & $\begin{array}{c}3.226 \\
00.000\end{array}$ & $\begin{array}{c}3.226 \\
00.000\end{array}$ & $\begin{array}{c}4.834 * * * \\
01.608\end{array}$ \\
\hline
\end{tabular}

- Each figure is the mean of the three replications.

-Figure with \pm sign in the bracket is standard deviation.

-Figure below the standard deviation is the increase for calculated parameter and percent increase for the others over the control. *: $\mathrm{P}<0.05 ; * *$ : $<0.005 ; * * *: \mathrm{P}<0.01$ 
Fig.1 The Parameters of Cocoon Spun by Mature fifth instar larvae of silkworm, Bombyx mori (L) [Race: Double Hybrid - (CSR6 x CSR26) x CSR2 x CSR27)] received topical application of acetone solution of Cucurbitacin-b at 48 hours after the fourth moult

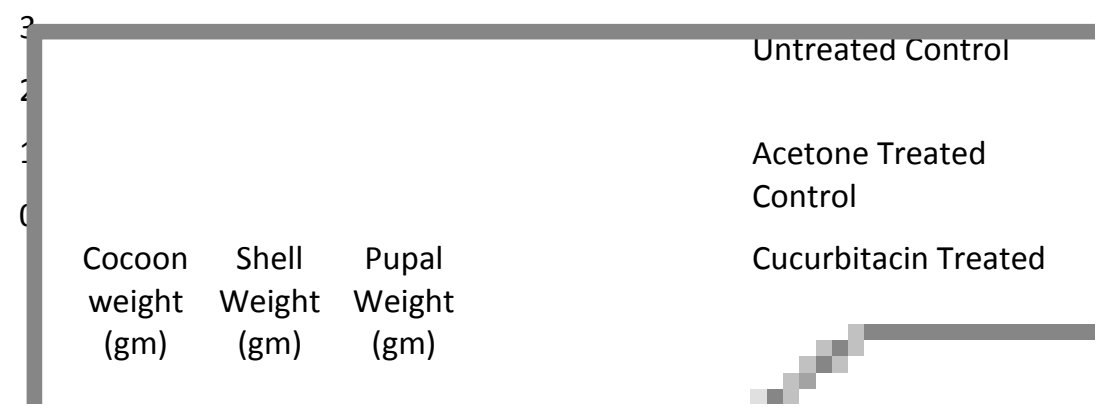

Fig.2 The shell ratio of Cocoon Spun by Mature fifth instar larvae of silkworm, Bombyx mori (L) [Race: Double Hybrid - (CSR6 x CSR26) x CSR2 x CSR27)] received topical application of acetone solution of Cucurbitacin-b at 48 hours after the fourth moult

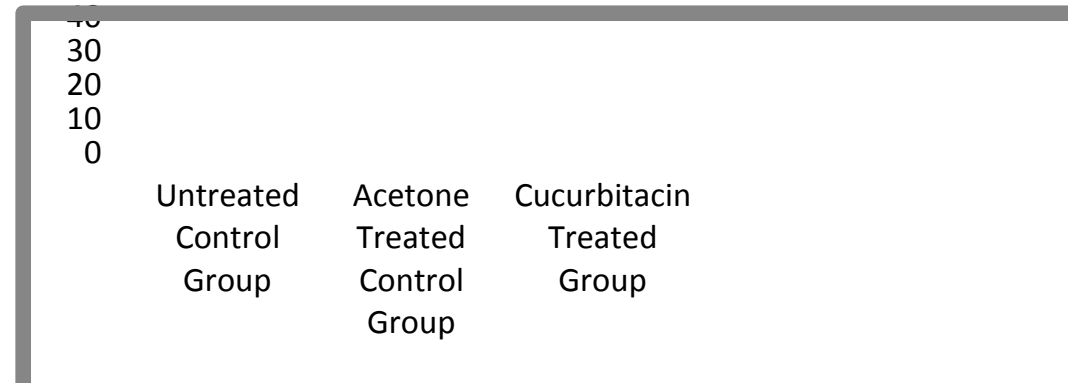

Fig.3 The parameters of silk fibre reeled from the Cocoon Spun by Mature fifth instar larvae of silkworm, Bombyx mori (L) [Race: Double Hybrid - (CSR6 x CSR26) x CSR2 x CSR27)] received topical application of acetone solution of Cucurbitacin-b at 48 hours after the fourth moult

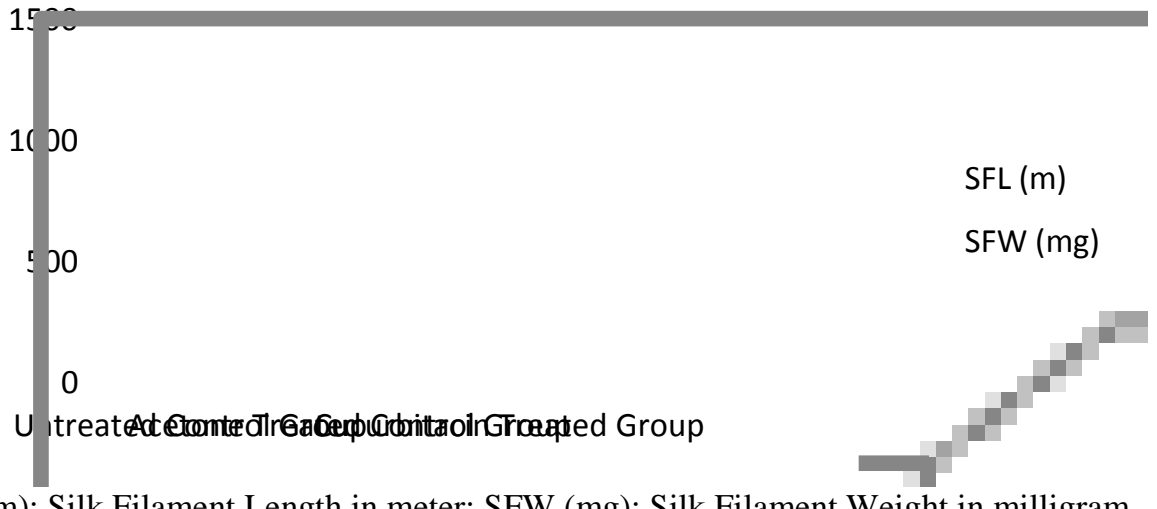

SFL (m): Silk Filament Length in meter; SFW (mg): Silk Filament Weight in milligram 
Fig.4 The denier scale of silk fibre reeled from the Cocoon Spun by Mature fifth instar larvae of silkworm, Bombyx mori (L) [Race: Double Hybrid - (CSR6 x CSR26) x CSR2 x CSR27)] received topical application of acetone solution of Cucurbitacin-b at 48 hours after the fourth moult

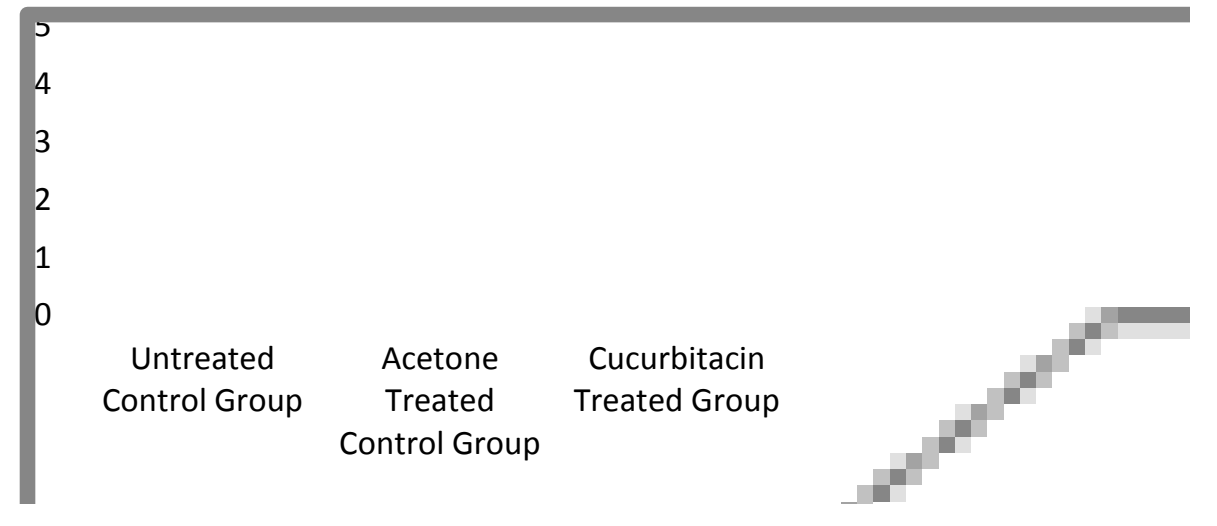

Plate.1

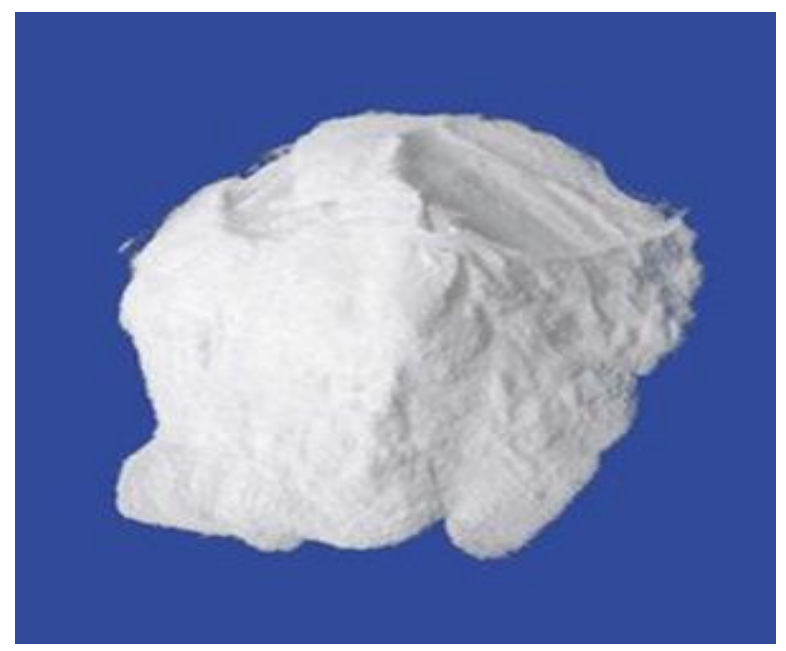

The silk cocoon spinned by mature fifthe instared larvae of silkworm, Bombyx mori (L) is foremost feature in sericultural practices. The silkworm cocoons are sole source for silk commercially available. The cocoons of silkworm are used to obtain the commercial silk fibre. According to Vitthalrao B. Khyade and Dhanashri R. Gaikawad (2016), most of the terpene compounds used for topical application to the larval instars of silkworm are the Juvenoids. Being member of terpene group, the Cucurbitacin-A may have Juvenoid activity in silkworm. The Cucurbitacin-A received by the fifth instared larvae of of silkworm, Bombyx mori (L) [Race: Double Hybrid - (CSR6 x CSR26) x CSR2 x CSR27)] larvae at 48 hours after the fourth moult in the present attempt may influence the appetite, nutrition and absorption of digested food. The terpene nature and insect juvenoid activity of Cucurbitacin-A may be responsible for accelerated growth of silk glands. Cocoon is in fact, a protective shell made up of a continuous and long proteinaceous silk 
filament spun by mature silkworm prior to pupation. Spinning the cocoon is for self protection from adverse climatic situations and natural enemies. The endogenous dosage of juvenoid (from endocrine system within the body of silkworm larvae themselseves) is concerned to stimulate hypermetabolism (Slama, 1971). The exogenous dosage of juvenoid (from environment, topically applied as in present attempt) is also concerned to stimulate hypermetabolism (Khyade, 2004). Use of Cucurbitacin-A through the acetone for topical application, thus chiefly reflected into the improvement of cocoon quality, shell ratio and silk filament quality (Vitthalrao B. Khyade, et al., (2005, 2006, 2007, 2008, 2009, 2010, 2011, 2012, 2013, 2014, 2015 and 2016).

The Cucurbitacin-A received through topical application may be utilized by the silkworm larvae for the extra synthesis of silk. The Cucurbitacin-A is one of the most popular tetracyclic terpenes and steroidal biocompound. Use of Cucurbitacin-A through acetone for rearing of silkworm larvae is much more easy method. Use of Cucurbitacin-A, a tetracyclic terpenes and steroidal biocompound may open a new avenue in sericulture for the quantative and qualitative field of cocoon and silk fibre.

Use of acetone solution of Cucurbitacin-A for topical application at 48 hours after the fourth moult to the fifth instared larvae of silkworm, Bombyx mori (L) [Race: Double Hybrid (CSR6 x CSR26) x CSR2 x CSR27)] was found significant influence on the parameteres of the silk cocoon and silk fibre. Being terpene compound, Cucurbitacin-A may have the juvenoid activity in the the fifth instared larvae of silkworm, Bombyx mori (L) [Race: Double Hybrid - (CSR6 x CSR26) x CSR2 x CSR27)]. Use of acetone solution of Cucurbitacin-A for topical application at 48 hours after the fourth moult to the fifth instared larvae of silkworm, Bombyx mori (L) is opening a new avenue in sericulture for qualitative silk yield.

\section{Acknowledgement}

Expertise support from Agricultural Development Trust, Baramati India deserve appreciations and exert a grand salutary influence.

\section{References}

Chen JC, Zhang GH, Zhang ZQ, Qiu MH, Zheng YT, Yang LM, Yu KB (January 2008). "Octanorcucurbitane and cucurbitane triterpenoids from the tubers of Hemsleya endecaphylla with HIV-1 inhibitory activity". Journal of Natural Products. 71 (1): 153-5. doi:10.1021/np0704396. PMID 18088099.

Kaushik U, Aeri V, Mir SR (2015). "Cucurbitacins - An insight into medicinal leads from nature". Pharmacognosy Reviews. 9 (17): $12-$ 8. doi:10.4103/0973-7847.156314. PMC 4441156. PMID 26009687.

Kusin S, Angert T, von Derau K, Horowitz BZ, Giffin S (2012). "189. Toxic Squash Syndrome: A case series of diarrheal illness following ingestion of bitter squash, 1999-2011" (PDF). 2012 Annual Meeting of the North American Congress of Clinical Toxicology (NACCT) October 1-6, 2012 las Vegas, NV, USA. 50 (7): 574-720. doi:10.3109/15563650.2012.700015.

Le Roux G, Leborgne I, Labadie M, Garnier $\mathrm{R}$, Sinno-Tellier S, Bloch $\mathrm{J}$, et al., (August 2018). "Poisoning by nonedible squash: retrospective series of 353 patients from French Poison Control Centers". Clinical Toxicology. 
$56 \quad$ (8): $\quad 790-794$. doi:10.1080/15563650.2018.1424891. PMID 29323540.

Mashilo J, Odindo AO, Shimelis HA, Musenge P, Tesfay SZ, Magwaza LS (2018). "Photosynthetic response of bottle gourd [Lagenaria siceraria (Molina) Standl.] to drought stress: Relationship between cucurbitacins accumulation and drought tolerance". Scientia Horticulturae. 231: 133-143. doi:10.1016/j.scienta.2017.12.027.

Eberhard Breitmaier (2006). Terpenes: Flavors, Fragrances, Pharmaca, Pheromones. Wiley-VCH. doi:10.1002/9783527609949. ISBN 9783527609949.

Davis, Edward M.; Croteau, Rodney (2000). Cyclization enzymes in the biosynthesis of monoterpenes, sesquiterpenes, and diterpenes. Topics in Current Chemistry. 209. pp. 53-95. doi:10.1007/3-540-48146-X_2. ISBN 978-3-540-66573-1.

Zaoral, M. and Slama, K. (1970). Peptides with juvenile hormone activity. Science.170:92-93.

Williams, C. M. (1956). The Juvenile Hormone of Insects. Nature.178:212213.

Gopakumar B.,Ambika, B. and Prabhu, V. K. K. (1977). Juvenmimetic activity in some south Indian plants and their probable cause of this activity in Morus alba (L). Entomon,2: 259-261.

Slama, K. (1971). Insect juvenile hormone analogues. Ann. Rev. Biochem.40:1079-1102.

Khyade, V. B., Patil, S. B., Khyade,S. V. and Bhawane G. P. (2002). Influence of acetone maceratives of Vitis vinifera on the larval parametersof silk worm, Bombyx mori (L). Indian Journal of Comparative Animal Physiology, 20:14-18.

Khyade V. B., Patil, S. B., Khyade, S. V. and
Bhawane, G. P. (2003).Influence of acetone maceratives of Vitis vinifera on the economic parameters of silk worm, Bombyx mori (L). Indian Journal of Comparative Animal Physiology.21: 28-32.

Khyade V. B. (2004). Influence of juvenoids on silk worm, Bombyx mori (L). Ph.D. Thesis, Shivaji University, Kolhapur, India.

Khyade, V.B. and Ganga V. Mhamane (2005). Vividh Vanaspati Arkancha Tuti Reshim Kitak Sangopanasathi Upyojana. Krishi Vdnyan. 4, 18-22.

Khyade, V. B.; Poonam B. Patil; M. Jaybhay; Rasika R. Gaikwad; Ghantaloo,U. S.;Vandana D. Shinde; Kavita H. Nimbalkar and Sarwade, J. P. (2007).Use of digoxin for improvement of economic parameters insilk worm, Bombyx mori (L). Bioinfrmatics (Zoological Society of India).

Grenier and Grenier (1983). Fenoxycarb, a fairlynew growth regulator: a review of its effects on insects. Ann. App. Biol.122: 369-403.

Kamimura M. and Kiguchi M. (1980). Effect of juvenile hormone analogue on fifth stadium larvae of silk worm, Bombyx mori (L) (Lepidoptera: Bombycidae). Appl. Entomol. Zool. 33(2): 333-338.

Ratnasen (1988).How does juvenile hormone cause more silk yield. Indian Silk:2122.

Mamatha, D. N., Nagalakshmma, K. and Rajeshwara Rao, M. (1999). Impact of selected Juvenile Hormone Mimics on the organic constituents of silk worm, Bombyx mori (L).

Krishnaswami, S., Narasimhana, M. N., Suryanarayana, S. K. and Kumaraj, S. (1978). Sericulture Manual -ll: Silk worm Rearing. F A O, United Nation's Rome: 131.

Vitthalrao B. Khyade and Karel Slama 
(2015). Screening of acetone solution of FME and Selected Monoterpene Compounds for Juvenile Hormone Activity Through Changes in pattern of Chitin Deposition in the Integument of Fifth instar larvae of silkworm, Bombyx mori (L) (PM x CSR2). IJBRITISH, 2(3) (2015) 68-90.

Norman, T. J. and Baily (1955). Some Problems in the Statistical Analysis of Epidemic Data. Statistical Methodology (Journal of Royal Statistical Society).

Rymal KS, Chambliss OL, Bond MD, Smith DA (April 1984). "Squash Containing Toxic Cucurbitacin Compounds Occurring in California and Alabama". Journal of Food Protection. 47 (4): 270-271. doi: $10.4315 / 0362-028 \mathrm{X}$ 47.4.270. PMID 30921968.

Martin, D. M.; Gershenzon, J.; Bohlmann, J. (July 2003). "Induction of Volatile Terpene Biosynthesis and Diurnal Emission by Methyl Jasmonate in Foliage of Norway Spruce". Plant Physiology. 132 (3): 1586-1599. doi:10.1104/pp.103.021196. PMC 167096. PMID 12857838.

Chen JC, Chiu MH, Nie RL, Cordell GA, Qiu SX (June 2005). "Cucurbitacins and cucurbitane glycosides: structures and biological activities". Natural Product Reports. $22 \quad$ (3): $\quad 386-99$. doi:10.1039/b418841c. PMID 16010347.

Pichersky, E. (10 February 2006). "Biosynthesis of Plant Volatiles:
Nature's Diversity and Ingenuity". Science. 311 (5762): 808-811. Bibcode:2006Sci...311..808P. doi:10.1126/science.1118510. PMC 2861909. PMID 16469917.

Alghasham AA (January 2013). "Cucurbitacins - a promising target for cancer therapy". International Journal of Health Sciences. 7 (1): 77-89. doi:10.12816/0006025. PMC 3612419. PMID 23559908.

Kapoor S (May 2013). "Cucurbitacin-A and its rapidly emerging role in the management of systemic malignancies besides lung carcinomas". Cancer Biotherapy \& Radiopharmaceuticals. 28

359.

doi:10.1089/cbr.2012.1373. PMID 23350897.

Wagner D (2015-08-21). "Auf den Geschmack kommt es an". Sueddeutsche.de. Retrieved 24 August 2015.

Assouly P (May 2018). "Hair Loss Associated With Cucurbit Poisoning". JAMA Dermatology. 154 (5): 617-618. doi:10.1001/jamadermatol.2017.6128. PMID 29590275.

Chen X, Bao J, Guo J, Ding Q, Lu J, Huang M, Wang Y (September 2012). "Biological activities and potential molecular targets of cucurbitacins: a focus on cancer". Anti-Cancer Drugs. 23 (8): 777-87. doi:10.1097/CAD.0b013e3283541384 . PMID 22561419. 
How to cite this article:

Dipali Dattatraya Ghanvat and Vitthalrao Bhimasha Khyade. 2020. The Influence of Topical Application of Acetone Solution of Cucurbitacin-A at 48 Hours After the Fourth Moult on the Parameters of Cocoon Spinned by Mature Fifth Instar Larvae of Silkworm, Bombyx mori (L) [Race: Double Hybrid - (CSR6 x CSR26) x CSR2 x CSR27)]. Int.J.Curr.Microbiol.App.Sci. 9(02): 1162-1174. doi: https://doi.org/10.20546/ijcmas.2020.902.137 